\title{
Properties of third-order half-linear dynamic equations with an unbounded neutral coefficient
}

\author{
Tongxing Li and Chenghui Zhang*
}

\section{"Correspondence:}

zchui@sdu.edu.cn

School of Control Science and

Engineering, Shandong University,

Jinan, Shandong 250061, P.R. China

\begin{abstract}
We study oscillation and asymptotic behavior of a class of third-order half-linear functional dynamic equations with an unbounded neutral coefficient. Several comparison theorems are presented that are essentially new.

MSC: 34K11;34N05;39A10
\end{abstract}

Keywords: asymptotic behavior; oscillation; neutral dynamic equation; third-order equation; time scale

\section{Introduction}

Neutral differential equations appear in modeling of the networks containing lossless transmission lines, in the study of vibrating masses attached to an elastic bar, as the Euler equation in some variational problems, in the theory of automatic control and in neuromechanical systems in which inertia plays an important role; see Hale [1].

A time scale $\mathbb{T}$ is an arbitrary nonempty closed subset of the reals, and the cases when this time scale is equal to the reals or to the integers represent the theories of differential and of difference equations. Not only does the new theory of the so-called dynamic equations unify the theories of differential equations and difference equations, but also extends these classical cases to cases 'in between', e.g., to the so-called $q$-difference equations, when $\mathbb{T}=q^{\mathbb{N}_{0}}:=\left\{q^{t}: t \in \mathbb{N}_{0}\right.$ for $\left.q>1\right\}$ (which has important applications in quantum theory (see [2])).

In this paper, we restrict our attention to oscillation and asymptotic behavior of the third-order half-linear neutral dynamic equation

$$
\left[r\left(z^{\Delta \Delta}\right)^{\gamma}\right]^{\Delta}(t)+q(t) x^{\gamma}(\delta(t))=0
$$

where $t \in\left[t_{0}, \infty\right)_{\mathbb{T}}:=\left[t_{0}, \infty\right) \cap \mathbb{T}, z:=x+p \cdot x \circ \tau$, and we assume that the following conditions are satisfied:

$\left(\mathrm{H}_{1}\right) \quad \gamma \leq 1$ is a quotient of odd positive integers;

$\left(\mathrm{H}_{2}\right) \quad p \in \mathrm{C}_{\mathrm{rd}}\left(\left[t_{0}, \infty\right)_{\mathbb{T}},[0, \infty)\right)$ and $q \in \mathrm{C}_{\mathrm{rd}}\left(\left[t_{0}, \infty\right)_{\mathbb{T}},(0, \infty)\right)$;

$\left(\mathrm{H}_{3}\right) r \in \mathrm{C}_{\mathrm{rd}}^{1}(\mathbb{T}, \mathbb{R}), \tau, \delta, \delta^{-1} \in \mathrm{C}_{\mathrm{rd}}^{1}(\mathbb{T}, \mathbb{T}), r(t)>0$, and $\lim _{t \rightarrow \infty} \tau(t)=\lim _{t \rightarrow \infty} \delta(t)=\infty$, where $\delta^{-1}$ denotes the inverse function of $\delta$;

@2013 Li and Zhang; licensee Springer. This is an Open Access article distributed under the terms of the Creative Commons Attribution License (http://creativecommons.org/licenses/by/2.0), which permits unrestricted use, distribution, and reproduction in any medium, provided the original work is properly cited. 
$\left(\mathrm{H}_{4}\right) \tau\left(\left[t_{0}, \infty\right)_{\mathbb{T}}\right)=\left[\tau\left(t_{0}\right), \infty\right)_{\mathbb{T}}, \delta^{-1}\left(\left[t_{0}, \infty\right)_{\mathbb{T}}\right)=\left[\delta^{-1}\left(t_{0}\right), \infty\right)_{\mathbb{T}}, \tau^{\Delta}>0$, and $\left(\delta^{-1}\right)^{\Delta}>0$.

We consider only those solutions $x$ of (1.1) which satisfy $\sup \left\{|x(t)|: t \in[T, \infty)_{\mathbb{T}}\right\}>0$ for all $T \in\left[t_{0}, \infty\right)_{\mathbb{T}}$ and assume that (1.1) possesses such solutions. As usual, a solution of (1.1) is called oscillatory if it has arbitrarily large generalized zeros on $\left[t_{0}, \infty\right)_{\mathbb{T}}$; otherwise, it is termed nonoscillatory.

In the last decade, a considerable number of studies have been made on oscillation and nonoscillation of solutions to various types of dynamic equations on time scales. We refer the reader to [3-30] and the references cited therein. For oscillation of dynamic equations, the authors in $[7,9,16,17,22,29]$ studied the first-order delay dynamic equation

$$
x^{\Delta}(t)+p(t) x(\tau(t))=0 .
$$

Agarwal et al. [4] considered the second-order delay dynamic equation

$$
x^{\Delta \Delta}(t)+p(t) x(\tau(t))=0 .
$$

See also Braverman and Karpuz [10]. Agarwal et al. [6] and Saker [23] investigated the second-order half-linear neutral delay dynamic equation

$$
\left[r\left(z^{\Delta}\right)^{\gamma}\right]^{\Delta}(t)+q(t) x^{\gamma}(t-\delta)=0
$$

where $z(t):=x(t)+p(t) x(t-\tau)$ and $0 \leq p(t)<1$. Regarding oscillation and asymptotic behavior of third-order dynamic equations, Erbe et al. [12] studied the equation

$$
x^{\Delta^{3}}(t)+p(t) x(t)=0 .
$$

Agarwal et al. [3] extended the results of [12] to the third-order delay dynamic equation

$$
\left(r_{1}\left(r_{2} x^{\Delta}\right)^{\Delta}\right)^{\Delta}(t)+q(t) x(\tau(t))=0
$$

Agarwal et al. [5], Hassan [14], and Li et al. [20, 21] examined equation (1.1) in the case where $p(t)=0$. Assuming $0 \leq p(t) \leq 1$ or $-1 \leq p(t) \leq 0$, Grace et al. [13], Saker and Graef [24], Yang [27, 28], and Zhang et al. [30] obtained some oscillation results for (1.1). The analogue for (1.1) in the case $\mathbb{T}=\mathbb{Z}$ has been studied in the recent paper by Thandapani and Kavitha [31].

So far, there are very few results for oscillation and asymptotic properties of (1.1) in the case

$$
\lim _{t \rightarrow \infty} p(t)=\infty
$$

Therefore, we use a comparison method to study (1.1) under the assumption that (1.2) is satisfied. In the sequel, all inequalities are assumed to hold eventually, that is, for all $t$ large enough. 


\section{Main results}

In what follows, $\tau^{-1}$ denotes the inverse function of $\tau$,

$$
\begin{aligned}
& Q(t):=\min \left\{q\left(\delta^{-1}(t)\right), q\left(\delta^{-1}(\tau(t))\right)\right\} \quad \text { and } \\
& H(t):=\max \left\{\frac{1}{\left(\delta^{-1}\right)^{\Delta}(t)}, \frac{p^{\gamma}(t)}{\left(\delta^{-1}\right)^{\Delta}(\tau(t)) \tau^{\Delta}(t)}\right\} .
\end{aligned}
$$

Before stating the main results, we begin with the following lemma.

Remark 2.1 It follows from assumptions $\left(\mathrm{H}_{3}\right),\left(\mathrm{H}_{4}\right)$, and [8, Theorem 1.93] that

$$
\left(y\left(\delta^{-1}(t)\right)\right)^{\Delta}=y^{\Delta}\left(\delta^{-1}(t)\right)\left(\delta^{-1}\right)^{\Delta}(t), \quad\left(y\left(\delta^{-1}(\tau(t))\right)\right)^{\Delta}=y^{\Delta}\left(\delta^{-1}(\tau(t))\right)\left(\delta^{-1}(\tau(t))\right)^{\Delta},
$$

and

$$
\left(\delta^{-1}(\tau(t))\right)^{\Delta}=\left(\delta^{-1}\right)^{\Delta}(\tau(t)) \tau^{\Delta}(t)
$$

where $y^{\Delta}$ exists for $t \in \mathbb{T}^{k}$.

Lemma 2.1 (See [29]) Assume $p(t) \geq 0, \tau(t) \leq t$, and $\lim _{t \rightarrow \infty} \tau(t)=\infty$. If

$$
\limsup _{t \rightarrow \infty} \sup _{\lambda \in E}\left\{\lambda \mathrm{e}_{-\lambda p}(t, \tau(t))\right\}<1, \quad \text { where } E:=\{\lambda \mid \lambda>0,1-\lambda p(t) \mu(t)>0\},
$$

then the delay dynamic inequality

$$
x^{\Delta}(t)+p(t) x(\tau(t)) \leq 0
$$

has no eventually positive solutions.

Lemma 2.2 (See [17]) Assume $p(t) \geq 0, \tau(t) \leq t$ and is nondecreasing with

$$
\lim _{t \rightarrow \infty} \tau(t)=\infty
$$

If there exists a $\lambda \in[0,1]$ such that

$$
\liminf _{t \rightarrow \infty} \int_{\tau(t)}^{t} p(s) \Delta s>\lambda \quad \text { and } \quad \limsup _{t \rightarrow \infty} \int_{\tau(t)}^{\sigma(t)} p(s) \Delta s>1-(1-\sqrt{1-\lambda})^{2},
$$

then the delay dynamic inequality (2.1) has no eventually positive solutions.

Lemma 2.3 Assume (1.2) and let

$$
\int_{t_{0}}^{\infty} \frac{\Delta t}{r^{1 / \gamma}(t)}=\infty
$$

If $x$ is a positive solution of (1.1) satisfying $\lim _{t \rightarrow \infty} x(t) \neq 0$, then $z$ satisfies

$$
z>0, \quad z^{\Delta}>0, \quad z^{\Delta \Delta}>0, \quad\left(r\left(z^{\Delta \Delta}\right)^{\gamma}\right)^{\Delta}<0,
$$

eventually. 
Proof Similar as in the proof of [30, Lemma 2.3], one obtains by (2.2) that either (2.3) holds or

$$
z>0, \quad z^{\Delta}<0, \quad z^{\Delta \Delta}>0, \quad\left(r\left(z^{\Delta \Delta}\right)^{\gamma}\right)^{\Delta}<0 .
$$

Since $\lim _{t \rightarrow \infty} p(t)=\infty$ and $\lim \sup _{t \rightarrow \infty} x(t)>0$ (which implies that $\limsup _{t \rightarrow \infty} x(\tau(t))>$ 0 by $\left.\left(\mathrm{H}_{4}\right)\right)$, it follows from $z(t) \geq p(t) x(\tau(t))$ that $\lim _{t \rightarrow \infty} z(t)=\infty$. Thus, the latter case cannot occur. The proof is complete.

Lemma 2.4 Assume that (2.3) is satisfied. Then

$$
z(t) \geq\left(r(t)\left(z^{\Delta \Delta}(t)\right)^{\gamma}\right)^{1 / \gamma} \int_{t_{1}}^{t} \frac{t-\sigma(s)}{r^{1 / \gamma}(s)} \Delta s
$$

Proof Since $r\left(z^{\Delta \Delta}\right)^{\gamma}$ is decreasing, we obtain

$$
z^{\Delta}(t) \geq z^{\Delta}(t)-z^{\Delta}\left(t_{1}\right)=\int_{t_{1}}^{t} \frac{\left(r(s)\left(z^{\Delta \Delta}(s)\right)^{\gamma}\right)^{1 / \gamma}}{r^{1 / \gamma}(s)} \Delta s \geq\left(r(t)\left(z^{\Delta \Delta}(t)\right)^{\gamma}\right)^{1 / \gamma} \int_{t_{1}}^{t} \frac{\Delta s}{r^{1 / \gamma}(s)} .
$$

Thus

$$
z(t) \geq\left(r(t)\left(z^{\Delta \Delta}(t)\right)^{\gamma}\right)^{1 / \gamma} \int_{t_{1}}^{t} \int_{t_{1}}^{u} \frac{1}{r^{1 / \gamma}(s)} \Delta s \Delta u
$$

By virtue of [15, Lemma 1], we have

$$
\int_{t_{1}}^{t} \int_{t_{1}}^{u} \frac{1}{r^{1 / \gamma}(s)} \Delta s \Delta u=\int_{t_{1}}^{t} \int_{\sigma(s)}^{t} \frac{1}{r^{1 / \gamma}(s)} \Delta u \Delta s=\int_{t_{1}}^{t} \frac{t-\sigma(s)}{r^{1 / \gamma}(s)} \Delta s
$$

Therefore, one has (2.4). This completes the proof.

Below, we assume that $t_{1} \in\left[t_{0}, \infty\right)_{\mathbb{T}}$ is large enough.

Theorem 2.1 Assume (1.2) and (2.2). If the first-order neutral dynamic inequality

$$
\left(y\left(\delta^{-1}(t)\right)+y\left(\delta^{-1}(\tau(t))\right)\right)^{\Delta}+\frac{Q(t)}{H(t)}\left(\int_{t_{1}}^{t} \frac{t-\sigma(s)}{r^{1 / \gamma}(s)} \Delta s\right)^{\gamma} y(t) \leq 0
$$

has no positive solutions, then every solution of (1.1) is oscillatory or tends to zero as $t \rightarrow \infty$.

Proof Let $x$ be a nonoscillatory solution of (1.1) and $\lim _{t \rightarrow \infty} x(t) \neq 0$. Without loss of generality, we may assume $x>0$ eventually. Then we have (2.3) due to Lemma 2.3. It follows from (1.1) and [8, Theorem 1.93] that for all sufficiently large $t$,

$$
\begin{aligned}
& \frac{\left(r\left(\delta^{-1}(t)\right)\left(z^{\Delta \Delta}\left(\delta^{-1}(t)\right)\right)^{\gamma}\right)^{\Delta}}{\left(\delta^{-1}\right)^{\Delta}(t)}+p^{\gamma}(t) \frac{\left(r\left(\delta^{-1}(\tau(t))\right)\left(z^{\Delta \Delta}\left(\delta^{-1}(\tau(t))\right)\right)^{\gamma}\right)^{\Delta}}{\left(\delta^{-1}(\tau(t))\right)^{\Delta}} \\
& +q\left(\delta^{-1}(t)\right) x^{\gamma}(t)+p^{\gamma}(t) q\left(\delta^{-1}(\tau(t))\right) x^{\gamma}(\tau(t))=0 .
\end{aligned}
$$


By virtue of [32, Lemma 2] and the definition of $z$, we obtain

$$
\begin{aligned}
q\left(\delta^{-1}(t)\right) x^{\gamma}(t)+p^{\gamma}(t) q\left(\delta^{-1}(\tau(t))\right) x^{\gamma}(\tau(t)) & \geq Q(t)\left[x^{\gamma}(t)+p^{\gamma}(t) x^{\gamma}(\tau(t))\right] \\
& \geq Q(t)[x(t)+p(t) x(\tau(t))]^{\gamma} \\
& =Q(t) z^{\gamma}(t) .
\end{aligned}
$$

Applications of (2.6) and (2.7) yield

$$
\begin{aligned}
& \frac{\left(r\left(\delta^{-1}(t)\right)\left(z^{\Delta \Delta}\left(\delta^{-1}(t)\right)\right)^{\gamma}\right)^{\Delta}}{\left(\delta^{-1}\right)^{\Delta}(t)}+p^{\gamma}(t) \frac{\left(r\left(\delta^{-1}(\tau(t))\right)\left(z^{\Delta \Delta}\left(\delta^{-1}(\tau(t))\right)\right)^{\gamma}\right)^{\Delta}}{\left(\delta^{-1}(\tau(t))\right)^{\Delta}} \\
& +Q(t) z^{\gamma}(t) \leq 0 .
\end{aligned}
$$

Therefore, we get by (2.8) and the definition of $H$ that

$$
\left(r\left(\delta^{-1}(t)\right)\left(z^{\Delta \Delta}\left(\delta^{-1}(t)\right)\right)^{\gamma}+r\left(\delta^{-1}(\tau(t))\right)\left(z^{\Delta \Delta}\left(\delta^{-1}(\tau(t))\right)\right)^{\gamma}\right)^{\Delta}+\frac{Q(t)}{H(t)} z^{\gamma}(t) \leq 0,
$$

which implies by (2.4) that

$$
\begin{aligned}
& \left(r\left(\delta^{-1}(t)\right)\left(z^{\Delta \Delta}\left(\delta^{-1}(t)\right)\right)^{\gamma}+r\left(\delta^{-1}(\tau(t))\right)\left(z^{\Delta \Delta}\left(\delta^{-1}(\tau(t))\right)\right)^{\gamma}\right)^{\Delta} \\
& \quad+\frac{Q(t)}{H(t)} r(t)\left(z^{\Delta \Delta}(t)\right)^{\gamma}\left(\int_{t_{1}}^{t} \frac{t-\sigma(s)}{r^{1 / \gamma}(s)} \Delta s\right)^{\gamma} \leq 0 .
\end{aligned}
$$

Thus, using $r\left(z^{\Delta \Delta}\right)^{\gamma}:=y$ in (2.9), one can see that $y$ is a positive solution of (2.5). This contradicts our assumptions and the proof is complete.

Applying additional conditions on the arguments of (2.5), one can deduce from Theorem 2.1 various criteria for (1.1).

Theorem 2.2 Assume (1.2), (2.2), and $\tau(t) \leq t$. If the first-order dynamic inequality

$$
w^{\Delta}(t)+\frac{Q(t)}{2 H(t)}\left(\int_{t_{1}}^{t} \frac{t-\sigma(s)}{r^{1 / \gamma}(s)} \Delta s\right)^{\gamma} w\left(\tau^{-1}(\delta(t))\right) \leq 0
$$

has no positive solutions, then every solution of (1.1) is oscillatory or tends to zero as $t \rightarrow \infty$.

Proof We assume that $x$ is a positive solution of (1.1) and $\lim _{t \rightarrow \infty} x(t) \neq 0$. As in the proof of Theorem 2.1, $y:=r\left(z^{\Delta \Delta}\right)^{\gamma}>0$ is decreasing and satisfies (2.5). Let us denote

$$
w(t):=y\left(\delta^{-1}(t)\right)+y\left(\delta^{-1}(\tau(t))\right) .
$$

It follows from $\tau(t) \leq t$ that

$$
w(t) \leq 2 y\left(\delta^{-1}(\tau(t))\right)
$$

Substituting this into (2.5), we get that $w$ is a positive solution of (2.10). This contradiction completes the proof. 
Corollary 2.1 Assume (1.2), (2.2), and $\tau(t) \leq t$. If $\delta(t) \leq \tau(t)$ and

$$
\limsup _{t \rightarrow \infty} \sup _{\lambda \in E}\left\{\lambda \mathrm{e}_{-\lambda Q_{1}}\left(t, \tau^{-1}(\delta(t))\right)\right\}<1
$$

where

$$
E:=\left\{\lambda \mid \lambda>0,1-\lambda Q_{1}(t) \mu(t)>0\right\} \quad \text { and } \quad Q_{1}(t):=\frac{Q(t)}{2 H(t)}\left(\int_{t_{1}}^{t} \frac{t-\sigma(s)}{r^{1 / \gamma}(s)} \Delta s\right)^{\gamma},
$$

then every solution of (1.1) is oscillatory or tends to zero as $t \rightarrow \infty$.

Proof According to Lemma 2.1, condition (2.12) guarantees that (2.10) has no positive solutions. Application of Theorem 2.2 completes the proof.

Corollary 2.2 Assume (1.2), (2.2), $\tau(t) \leq t$, and $\delta(t) \leq \tau(t)$. If there exists a $\lambda \in[0,1]$ such that

$$
\liminf _{t \rightarrow \infty} \int_{\tau^{-1}(\delta(t))}^{t} Q_{1}(s) \Delta s>\lambda \quad \text { and } \quad \limsup _{t \rightarrow \infty} \int_{\tau^{-1}(\delta(t))}^{\sigma(t)} Q_{1}(s) \Delta s>1-(1-\sqrt{1-\lambda})^{2}
$$

where $Q_{1}$ is defined as in Corollary 2.1, then every solution of (1.1) is oscillatory or tends to zero as $t \rightarrow \infty$.

Proof By virtue of Lemma 2.2, condition (2.13) implies that (2.10) has no positive solutions. Application of Theorem 2.2 yields the result.

Theorem 2.3 Assume (1.2), (2.2), and $\tau(t) \geq t$. If the first-order dynamic inequality

$$
w^{\Delta}(t)+\frac{Q(t)}{2 H(t)}\left(\int_{t_{1}}^{t} \frac{t-\sigma(s)}{r^{1 / \gamma}(s)} \Delta s\right)^{\gamma} w(\delta(t)) \leq 0
$$

has no positive solutions, then every solution of (1.1) is oscillatory or tends to zero as $t \rightarrow \infty$.

Proof We assume that $x$ is a positive solution of (1.1) and $\lim _{t \rightarrow \infty} x(t) \neq 0$. As in the proof of Theorem 2.1, $y:=r\left(z^{\Delta \Delta}\right)^{\gamma}>0$ is decreasing and satisfies (2.5). We denote $w$ by (2.11). In view of $\tau(t) \geq t$, we obtain

$$
w(t) \leq 2 y\left(\delta^{-1}(t)\right)
$$

Substitution of this term into (2.5) implies that $w$ is a positive solution of (2.14). This contradiction completes the proof.

Corollary 2.3 Assume (1.2), (2.2), and $\tau(t) \geq t$. If $\delta(t) \leq t$ and

$$
\limsup _{t \rightarrow \infty} \sup _{\lambda \in E}\left\{\lambda \mathrm{e}_{-\lambda Q_{1}}(t, \delta(t))\right\}<1,
$$

where $E$ and $Q_{1}$ are defined as in Corollary 2.1, then every solution of (1.1) is oscillatory or tends to zero as $t \rightarrow \infty$. 
Proof By virtue of Lemma 2.1, condition (2.15) ensures that (2.14) has no positive solutions. Application of Theorem 2.3 yields the result.

Corollary 2.4 Assume (1.2), (2.2), $\tau(t) \geq t$, and $\delta(t) \leq t$. If there exists $a \lambda \in[0,1]$ such that

$$
\liminf _{t \rightarrow \infty} \int_{\delta(t)}^{t} Q_{1}(s) \Delta s>\lambda \quad \text { and } \quad \limsup _{t \rightarrow \infty} \int_{\delta(t)}^{\sigma(t)} Q_{1}(s) \Delta s>1-(1-\sqrt{1-\lambda})^{2}
$$

where $Q_{1}$ is defined as in Corollary 2.1, then every solution of (1.1) is oscillatory or tends to zero as $t \rightarrow \infty$.

Proof By Lemma 2.2, condition (2.16) guarantees that (2.14) has no positive solutions. Application of Theorem 2.3 completes the proof.

Remark 2.2 Note that oscillation results can be also obtained for $\gamma \geq 1$; in this case, one simply has to replace $Q$ in [32, Lemma 1] with a function $Q / 2^{\gamma-1}$ and proceed as above.

Example 2.1 For $t \geq 1$, consider the third-order neutral differential equation

$$
[x(t)+t x(t-1)]^{\prime \prime \prime}+\left[\mathrm{e}^{-2}+(t-3) \mathrm{e}^{-1}\right] x(t-2)=0 .
$$

It is not difficult to verify that $Q(t) / H(t) \geq 1$. Applications of Theorem 2.2 and [18, Theorem 2.1.1] imply that every solution of (2.17) is oscillatory or satisfies $\lim _{t \rightarrow \infty} x(t)=0$. As a matter of fact, one such solution is $x(t)=\mathrm{e}^{-t}$.

Remark 2.3 Some other examples may be given easily. For instance, we take $\tau(t)=t-\tau_{0}$ and $\delta(t)=t-\delta_{0}$ for $\mathbb{T}=\mathbb{Z}$, we put $\tau(t)=t+h k$ and $\delta(t)=t-h k$ for $\mathbb{T}=h \mathbb{Z}:=\{h k: k \in \mathbb{Z}\}$, we set $\tau(t)=q t$ and $\delta(t)=t / q$ for $\mathbb{T}=q^{\mathbb{N}_{0}}$, etc.

\section{Competing interests}

The authors declare that they have no competing interests.

\section{Authors' contributions}

All authors contributed equally to this work. They all read and approved the final version of the manuscript.

\section{Acknowledgements}

The authors express their sincere gratitude to the anonymous referees for the careful reading of the original manuscript and useful comments that helped to improve the presentation of the results and accentuate important details. This research is supported by National Key Basic Research Program of P.R. China (Grant No. 2013CB035604) and NNSF of P.R. China (Grant Nos. 61034007, 51277116, 51107069).

Received: 1 July 2013 Accepted: 21 October 2013 Published: 19 Nov 2013

\section{References}

1. Hale, JK: Theory of Functional Differential Equations. Springer, New York (1977)

2. Kac, V, Cheung, P: Quantum Calculus. Springer, New York (2002)

3. Agarwal, RP, Bohner, M, Li, T, Zhang, C: Hille and Nehari type criteria for third-order delay dynamic equations. J. Differ. Equ. Appl. 19, 1563-1579 (2013)

4. Agarwal, RP, Bohner, M, Saker, SH: Oscillation of second order delay dynamic equations. Can. Appl. Math. Q. 13, 1-17 (2005)

5. Agarwal, RP, Bohner, M, Tang, S, Li, T, Zhang, C: Oscillation and asymptotic behavior of third-order nonlinear retarded dynamic equations. Appl. Math. Comput. 219, 3600-3609 (2012)

6. Agarwal, RP, O'Regan, D, Saker, SH: Oscillation criteria for second-order nonlinear neutral delay dynamic equations. J. Math. Anal. Appl. 300, 203-217 (2004)

7. Bohner, M: Some oscillation criteria for first order delay dynamic equations. Far East J. Appl. Math. 18, 289-304 (2005) 
8. Bohner, M, Peterson, A: Dynamic Equations on Time Scales: An Introduction with Applications. Birkhäuser, Boston (2001)

9. Braverman, E, Karpuz, B: Nonoscillation of first-order dynamic equations with several delays. Adv. Differ. Equ. 2010 $1-22(2010)$

10. Braverman, E, Karpuz, B: Nonoscillation of second-order dynamic equations with several delays. Abstr. Appl. Anal. 2011, 1-34 (2011)

11. Erbe, $L$, Mert, R, Peterson, A, Zafer, A: Oscillation of even order nonlinear delay dynamic equations on time scales. Czechoslov. Math. J. 63, 265-279 (2013)

12. Erbe, L, Peterson, A, Saker, SH: Hille and Nehari type criteria for third-order dynamic equations. J. Math. Anal. Appl. 329, 112-131 (2007)

13. Grace, SR, Graef, JR, El-Beltagy, MA: On the oscillation of third order neutral delay dynamic equations on time scales. Comput. Math. Appl. 63, 775-782 (2012)

14. Hassan, TS: Oscillation of third order nonlinear delay dynamic equations on time scales. Math. Comput. Model. 49, 1573-1586 (2009)

15. Karpuz, B: Unbounded oscillation of higher-order nonlinear delay dynamic equations of neutral type with oscillating coefficients. Electron. J. Qual. Theory Differ. Equ. 34, 1-14 (2009)

16. Karpuz, B: Li type oscillation theorem for delay dynamic equations. Math. Methods Appl. Sci. 36, 993-1002 (2013)

17. Karpuz, B, Öcalan, Ö: New oscillation tests and some refinements for first-order delay dynamic equations (submitted)

18. Ladde, GS, Lakshmikantham, V, Zhang, BG: Oscillation Theory of Differential Equations with Deviating Arguments. Marcel Dekker, New York (1987)

19. Li, T, Han, Z, Sun, S, Yang, D: Existence of nonoscillatory solutions to second-order neutral delay dynamic equations on time scales. Adv. Differ. Equ. 2009, 1-10 (2009)

20. Li, T, Han, Z, Sun, Y, Zhao, Y: Asymptotic behavior of solutions for third-order half-linear delay dynamic equations on time scales. J. Appl. Math. Comput. 36, 333-346 (2011)

21. Li, T, Han, Z, Zhang, C, Sun, Y: Oscillation criteria for third-order Emden-Fowler delay dynamic equations on time scales. Acta Math. Sci., Ser. A 32, 222-232 (2012)

22. Şahiner, Y, Stavroulakis, IP: Oscillations of first order delay dynamic equations. Dyn. Syst. Appl. 15, $645-656$ (2006)

23. Saker, SH: Oscillation of second-order nonlinear neutral delay dynamic equations on time scales. J. Comput. Appl. Math. 187, 123-141 (2006)

24. Saker, SH, Graef, JR: Oscillation of third-order nonlinear neutral functional dynamic equations on time scales. Dyn. Syst. Appl. 21, 583-606 (2012)

25. Şenel, MT: Behavior of solutions of a third-order dynamic equation on time scales. J. Inequal. Appl. 2013, 1-7 (2013)

26. Thandapani, E, Piramanantham, V: Oscillation criteria of second order neutral delay dynamic equations with distributed deviating arguments. Electron. J. Qual. Theory Differ. Equ. 61, 1-15 (2010)

27. Yang, J: Oscillation criteria for certain third-order variable delay functional dynamic equations on time scales. J. Appl. Math. Comput. 43, 445-466 (2013)

28. Yang, J: Oscillation criteria for certain third-order delay dynamic equations. Adv. Differ. Equ. 2013, 1-13 (2013)

29. Zhang, BG, Deng, XH: Oscillation of delay differential equations on time scales. Math. Comput. Model. 36, 1307-1318 (2002)

30. Zhang, C, Saker, SH, Li, T: Oscillation of third-order neutral dynamic equations on time scales. Dyn. Contin. Discrete Impuls. Syst., Ser. B, Appl. Algorithms 20, 333-358 (2013)

31. Thandapani, E, Kavitha, N: Oscillatory behavior of solutions of certain third order mixed neutral difference equations. Acta Math. Sci. 33, 218-226 (2013)

32. Baculíková, B, Džurina, J: Oscillation theorems for second-order nonlinear neutral differential equations. Comput. Math. Appl. 62, 4472-4478 (2011)

\section{Submit your manuscript to a SpringerOpen ${ }^{\ominus}$ journal and benefit from:}

- Convenient online submission

Rigorous peer review

- Immediate publication on acceptance

- Open access: articles freely available online

- High visibility within the field

- Retaining the copyright to your article 